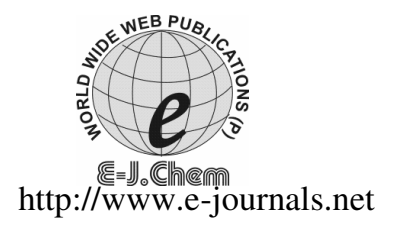

ISSN: 0973-4945; CODEN ECJHAO

E-Journal of Chemistry

2011, 8(4), 1728-1733

\title{
Kinetics and Mechanism of Oxidation of Isoleucine by $N$-Bromophthalimide in Aqueous Perchloric Acid Medium
}

\author{
N.M.I. ALHAJI* ${ }^{*}$ and S. SOFIYA LAWRENCE MARY \\ P.G. and Research Department of Chemistry \\ Khadir Mohideen College, Adirampattinam - 614 701, India \\ alhajinmi@yahoo.in
}

Received 20 April 2011; Accepted 25 June 2011

\begin{abstract}
The kinetics of oxidation of isoleucine with $N$-bromophthalimide has been studied in perchloric acid medium potentiometrically. The reaction is of first order each in [NBP] and [amino acid] and negative fractional order in $\left[\mathrm{H}^{+}\right]$. The rate is decreased by the addition of phthalimide. A decrease in the dielectric constant of the medium increases the rate. Addition of halide ions or acrylonitrile has no effect on the kinetics. Similarly, variation of ionic strength of the medium does not affect the reaction rate. The reaction rate has been determined at different temperatures and activation parameters have been calculated. A suitable mechanism involving hypobromous acid as reactive species has been proposed.
\end{abstract}

Keywords: Potentiometry, $N$-Bromophthalimide, Isoleucine, Oxidation, Mechanism

\section{Introduction}

Essential amino acids such as valine, leucine, isoleucine, methionine and phenylalanine, etc. serve important functions in our biological system and play a significant role in metabolism. These amino acids are used in biochemical, microbiological and nutrition investigation and are employed as dietary supplements. Isoleucine also finds applications in medicine and pharmaceuticals. The present investigation is a part of our broad program of studying mechanistic aspects of the oxidation of amino acids by $N$-halo compounds. There are many reports on the kinetics of oxidation of amino acids by various $N$-halo oxidants, such as $N$-bromoacetamide ${ }^{1}$, benzyltrimethyl ammonium tribromide ${ }^{2}, N$-bromosuccinimide ${ }^{3}$, chloramine- $\mathrm{T}^{4-6}$, bromamine- $\mathrm{T}^{7}$, chloramine- $\mathrm{B}^{8}$, bromamine- $\mathrm{B}^{9}, N$-bromonicotinimide ${ }^{10}$, $N$-chlorosaccharin ${ }^{11}, N$-bromophthalimide ${ }^{12}$ etc. Here we report the results of the kinetic studies of the oxidation of isoleucine(Ile) with $\mathrm{N}$-bromophthalimide (NBP) in aqueous perchloric acid medium. 


\section{Experimental}

$\mathrm{N}$-Bromophthalimide (Aldrich), purity $99 \%$ was used as received. The standard solution in distilled water was prepared afresh every week and standardized against thio. Chromatographically pure isoleucine (SRL, India) was further assayed by acetous perchloric method $^{13}$. All other chemicals were of Analar grade. Ionic strength of the medium was kept constant by using sodium perchlorate.

\section{Kinetic measurements}

The reactions were carried out under pseudo-first order conditions by keeping an excess (x10 or greater) of the amino acid over NBP. The kinetics has been followed potentiometrically by setting up a cell made up of the reaction mixture in which platinum electrode and a standard calomel electrode were dipped. The EMF of the cell was measured periodically using an Equip-tronics potentiometer, while the reaction mixture was continuously stirred using a magnetic stirrer. The pseudo first-order rate constants $\left(\mathrm{k}_{\mathrm{obs}}\right)$ were calculated from the slopes of $\ln \left(\mathrm{E}_{\mathrm{t}}-\mathrm{E}_{\infty}\right)$ versus time plots $(\mathrm{r}>0.990)$ and the results were reproducible to an accuracy of $\pm 5 \%$. The second-order rate constants $\left(k_{2}\right)$ were obtained as $k_{\text {obs }} /[$ Ile] .

\section{Stoichiometry and product analysis}

The reaction between $N$-bromophthalimide $(0.05 \mathrm{M})$ and isoleucine $(0.01 \mathrm{M})$ was conducted in $100 \mathrm{~mL}$ of water in the presence of perchloric acid $(0.1 \mathrm{M})$. The reaction was allowed to proceed for 24 hours to ensure the completion of the reaction. The residual $\mathrm{N}$-bromophthalimide was determined iodometrically. With varying amounts of isoleucine the analysis showed that $2 \mathrm{~mol}$ of $\mathrm{N}$-bromophthalimide were consumed for $1 \mathrm{~mol}$ of the amino acid. This occurs because the aldehyde, initial product of the oxidation, was further oxidized to the corresponding carboxylic acid in the presence of an excess of the oxidant.

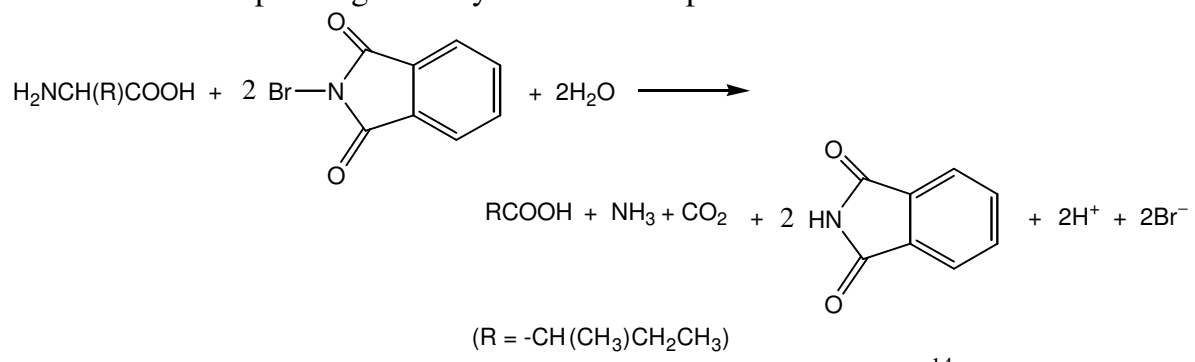

The formation of carboxylic acid product was confirmed by spot tests ${ }^{14}$ and ammonium ions by Nessler's reagent. The liberated $\mathrm{CO}_{2}$ was predicted by lime ware test.

\section{Results and Discussion}

Kinetics of oxidation of isoleucine by $\mathrm{N}$-bromophthalimide was investigated at several initial concentrations of the reactants in $\mathrm{HClO}_{4}$ medium under pseudo-first order conditions of $[$ substrate $]>>[\mathrm{NBP}]$. At constant $[\mathrm{Ile}]_{\mathrm{o}},\left[\mathrm{HClO}_{4}\right],\left[\mathrm{NaClO}_{4}\right]$ and temperature, plots of $\ln \left(\mathrm{E}_{\mathrm{t}}-\mathrm{E}_{\infty}\right)$ vs. time were linear $(\mathrm{r}>0.993)$ indicating first-order dependence of rate on $[\mathrm{NBP}]_{\mathrm{o}}$. Further, the rate constants remained constant with increase in the concentration of NBP (Table 1), confirming first-order dependence on $[\mathrm{NBP}]_{\mathrm{o}}$. Also, the rate data in Table 1 point out that $k_{o b s}$ value increases linearly with increase in the initial concentration of isoleucine. A plot of $\log k_{o b s} v s . \log$ [Ile] $]_{0}$ was linear $(\mathrm{r}=0.999)$ with a slope value of 0.98 . Also the plot of $k_{o b s} v s$. [Ile] o passed through the origin (Figure $1 ; \mathrm{r}=0.999$ ), establishing the 
first order dependence of rate on $[\mathrm{Ile}]_{0}$. The rate decreased with increase in $\left[\mathrm{HClO}_{4}\right]$ (Table 1) and the plot of $\log k_{o b s} v s . \log \left[\mathrm{H}^{+}\right]_{\mathrm{o}}$ was found to be linear ((Figure 2; $\mathrm{r}=0.993$; slope $=-0.52$ ) showing a negative fractional-order dependence on $\left[\mathrm{H}^{+}\right]_{\mathrm{o}}$. Further, the plot of $k_{\text {obs }} v s .1 /\left[\mathrm{H}^{+}\right]_{\mathrm{o}}$ was linear and passed through the origin, indicating that the oxidation occurred only through the acid dependent path under these conditions.

Table 1. Pseudo first-order and second-order rate constants for the oxidation of isoleucine by NBP in aqueous perchloric acid at $303 \mathrm{~K}^{\mathrm{a}, \mathrm{b}}$

\begin{tabular}{ccccc}
\hline $10^{3}[\mathrm{Ile}]_{\mathrm{o}}, \mathrm{M}$ & $10^{4}[\mathrm{NBP}]_{\mathrm{o}}, \mathrm{M}$ & $10^{2}\left[\mathrm{H}^{+}\right]_{\mathrm{o}}, \mathrm{M}$ & $10^{4} k_{\mathrm{obs}}{ }^{\mathrm{c}}, \mathrm{s}^{-1}$ & $10^{2} k_{2}{ }^{\mathrm{d}}, \mathrm{M}^{-1} \mathrm{~s}^{-1}$ \\
\hline 2.0 & 2.0 & 4.0 & $2.95 \pm 0.27$ & $14.6 \pm 1.4$ \\
4.0 & 2.0 & 4.0 & $5.76 \pm 0.51$ & $14.4 \pm 1.3$ \\
8.0 & 2.0 & 4.0 & $11.7 \pm 1.1$ & $14.7 \pm 1.4$ \\
12.0 & 2.0 & 4.0 & $17.5 \pm 1.6$ & $14.6 \pm 1.4$ \\
20.0 & 2.0 & 4.0 & $27.8 \pm 2.8$ & $13.9 \pm 1.4$ \\
4.0 & 0.5 & 0.4 & $5.68 \pm 0.52$ & $14.2 \pm 1.3$ \\
4.0 & 1.0 & 4.0 & $5.71 \pm 0.53$ & $14.3 \pm 1.3$ \\
4.0 & 3.0 & 4.0 & $5.82 \pm 0.54$ & $14.6 \pm 1.4$ \\
4.0 & 2.0 & 2.0 & $7.35 \pm 0.70$ & $18.4 \pm 1.7$ \\
4.0 & 2.0 & 8.0 & $4.16 \pm 0.39$ & $10.4 \pm 1.0$ \\
4.0 & 2.0 & 12.0 & $3.08 \pm 0.31$ & $7.71 \pm 0.78$ \\
4.0 & 2.0 & 20.0 & $2.26 \pm 0.21$ & $5.67 \pm 0.53$ \\
\hline
\end{tabular}

${ }^{a}$ As determined by a potentiometric technique following the disappearance of NBP; the error quoted in $k$ values is the $95 \%$ confidence limit of 'Student $t$ test ${ }^{I 5}$. ${ }^{b}$ General conditions: $[I]=0.75 \mathrm{M}$; ${ }^{c}$ Estimated from pseudo first-order plots over $60 \%$ reaction. ${ }^{d}$ Individual $k_{2}$ values estimated as $k_{o b s} /[I l e]_{0}$

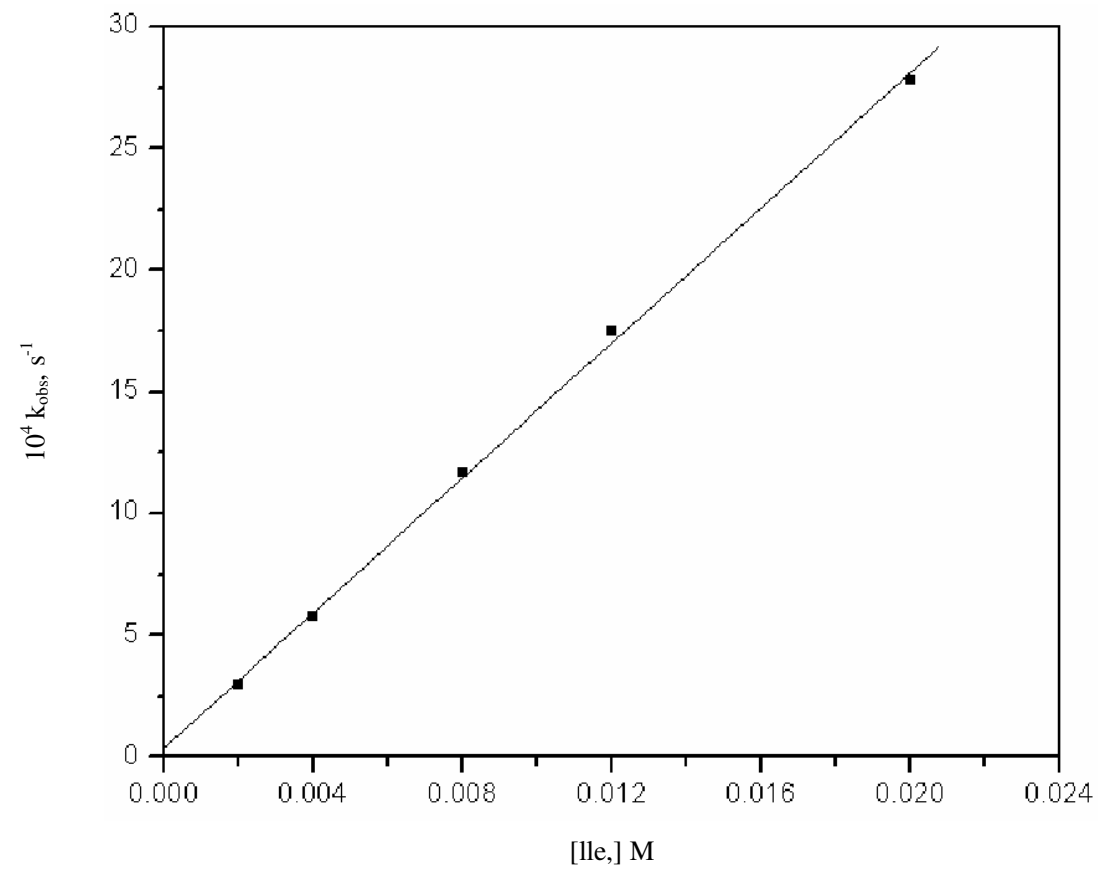

Figure 1. Direct plot of $k_{o b s}$ versus [amino acid] for the oxidation of isoleucine with NBP 


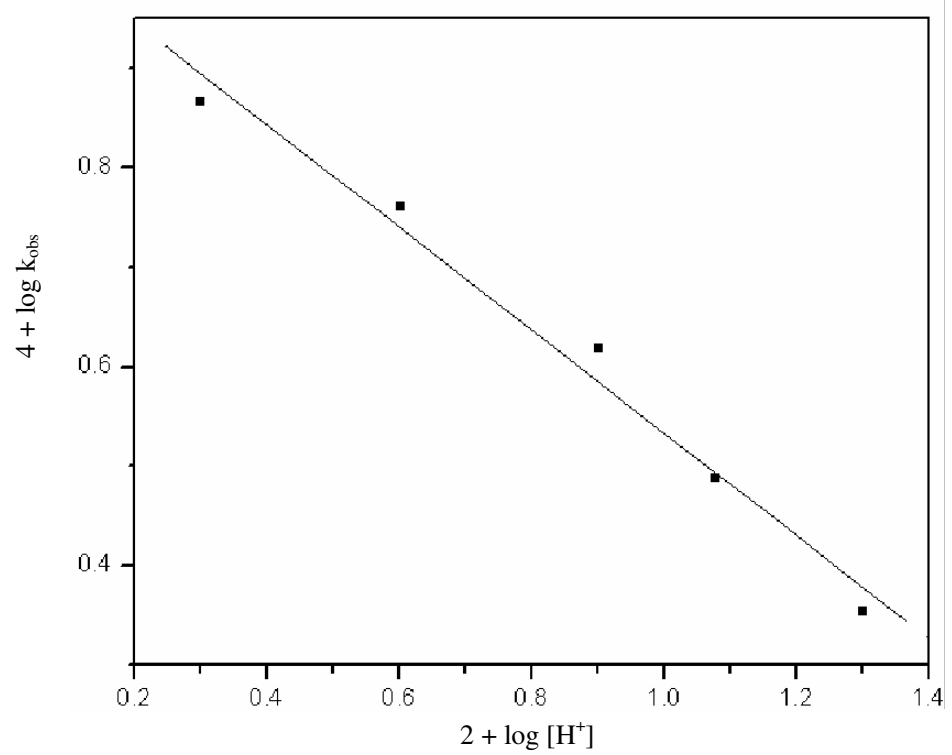

Figure 2. Double logarithmic plot for the oxidation of isoleucine with NBP

The rate of the reaction is not significantly affected by the change in the ionic strength of the medium (Table 2) brought about by the addition of sodium perchlorate, pointing out the participation of a neutral species as a reactant in the rate-determining step. Addition of phthalimide causes a decrease in the rate of reaction (Table 2) suggesting that the step in which phthalimide is formed as one of the products is reversible.

Table 2. Influence of ionic strength and phthalimide (NHP) on reaction rate for the oxidation of isoleucine with NBP at $303 \mathrm{~K}^{\mathrm{a}}$

\begin{tabular}{cccc}
\hline$[\mathrm{I}], \mathrm{M}$ & $10^{4} k_{\text {obs }}, \mathrm{s}^{-1}$ & $10^{4}[\mathrm{NHP}], \mathrm{M}$ & $10^{4} k_{\text {obs }}, \mathrm{s}^{-1}$ \\
\hline 0.50 & $5.79 \pm 0.54$ & 0 & $5.76 \pm 0.51$ \\
0.75 & $5.76 \pm 0.51$ & 1.0 & $5.28 \pm 0.49$ \\
1.00 & $5.81 \pm 0.55$ & 3.0 & $4.59 \pm 0.46$ \\
\hline
\end{tabular}

${ }^{a}$ General conditions: $[\mathrm{NBP}]=0.0002 \mathrm{M} ;[$ Ile $]=0.004 \mathrm{M} ;\left[\mathrm{H}^{+}\right]=0.04 \mathrm{M} ;[\mathrm{I}]=0.75 \mathrm{M}$ unless otherwise stated

The involvement of free-radical intermediates during the reaction can be excluded as the rate constant is not affected by the addition of acrylonitrile (Table 3). The added KBr has no effect on the rate of oxidation (Table 3), establishing that the course of the oxidation does not involve $\mathrm{Br}^{+}$ion or $\mathrm{Br}_{2}$ as active species. Addition of acetonitrile to the reaction mixture increased the rate (Table 3 ) and a plot of $\log k_{o b s} v s .1 / \mathrm{D}$ is linear with a positive slope.

Table 3. Influence of added acrylonitrile ( $\mathrm{AN}$ ), $\mathrm{KBr}$ and solvent polarity on reaction rate for the oxidation of isoleucine with NBP at $303 \mathrm{~K}^{\mathrm{a}}$

\begin{tabular}{cccccc}
\hline$[\mathrm{AN}], \mathrm{M}$ & $10^{4} k_{\text {obs }}, \mathrm{s}^{-1}$ & {$[\mathrm{KBr}], \mathrm{M}$} & $10^{4} k_{o b s}, \mathrm{~s}^{-1}$ & $\% \mathrm{CH}_{3} \mathrm{CN}, \mathrm{v} / \mathrm{v}^{\mathrm{b}}$ & $10^{4} k_{o b s}, \mathrm{~s}^{-1}$ \\
\hline 0 & $5.76 \pm 0.51$ & 0 & $5.76 \pm 0.51$ & 0 & $5.76 \pm 0.51$ \\
0.003 & $5.78 \pm 0.52$ & 0.001 & $5.72 \pm 0.52$ & 10 & $6.92 \pm 0.59$ \\
0.006 & $5.74 \pm 0.52$ & 0.004 & $5.69 \pm 0.55$ & 20 & $8.84 \pm 0.72$ \\
\multicolumn{7}{c}{ General conditions: $[\mathrm{NBP}]=0.0004 \mathrm{M} ;[$ [lle $]=0.004 \mathrm{M} ;\left[\mathrm{H}^{+}\right]=0.04 \mathrm{M} ;[\mathrm{II}]=0.75 \mathrm{M}$}
\end{tabular}


The reaction was studied at three other temperatures (298, 308 and $318 \mathrm{~K})$ keeping other experimental conditions constant. From the Arrehenius and Eyring plots, the thermodynamic parameters for the oxidation of isoleucine were found to be $\mathrm{E}_{\mathrm{a}}=49.42$ $\mathrm{kJ} / \mathrm{mol}, \Delta H^{\neq}=46.86 \mathrm{~kJ} / \mathrm{mol}, \Delta G^{\neq}(298 \mathrm{~K})=78.56 \mathrm{~kJ} / \mathrm{mol}$ and $\Delta S^{\neq}=106.39 \mathrm{JK}^{1} \mathrm{~mol}^{1}$.

\section{Mechanism}

The possible oxidation species in acidified NBP solution are $\mathrm{NBP}, \mathrm{NBPH}^{+}, \mathrm{HOBr}$ and $\mathrm{H}_{2} \mathrm{OBr}^{+}$. In the present study the involvement of $\mathrm{NBPH}^{+}$can be ruled out on the basis that the reaction shows a negative dependence on $\left[\mathrm{H}^{+}\right]$. Molecular bromine or bromonium ion the reactive species may not be the reactive species here because the addedBr has no effect on the rate of the reaction in present study. The retarding effect of phthalimide suggest that the pre-equilibrium step involves a process in which phthalimide is one of the products.

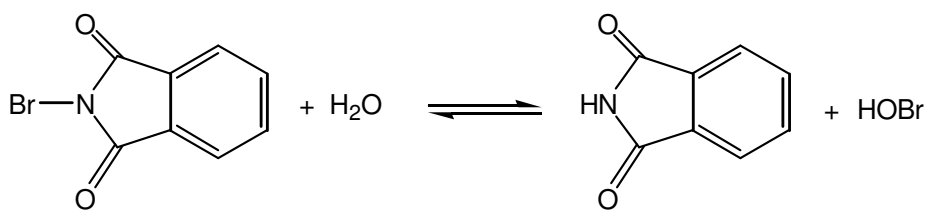

Therefore, it can be assumed that $\mathrm{HOBr}$ is the most likely oxidizing species in the present reaction. In aqueous solution amino acids exist in the following equilibrium.

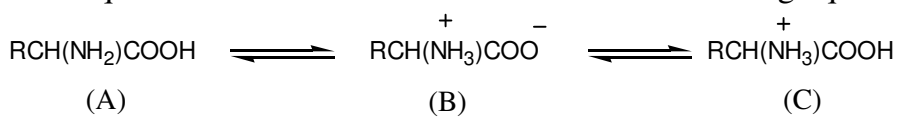

The linear decrease in the rate with an increase in the concentration of $\mathrm{H}^{+}$in the reaction mixture suggests that the amino acid is being removed progressively as kinetically inactive forms (B) and (C), thus establishing that the amino acid involves in the reaction in the form (A). Based on the foregoing discussions, the following mechanism (Scheme 1) involving an electrophilic attack of $\mathrm{HOBr}$ on the amino group of the amino acid has been proposed. A similar mechanism has been postulated in the oxidation of amino acids by chloramine- $\mathrm{T}^{16}$ and $N$-bromoacetamide ${ }^{1}$.

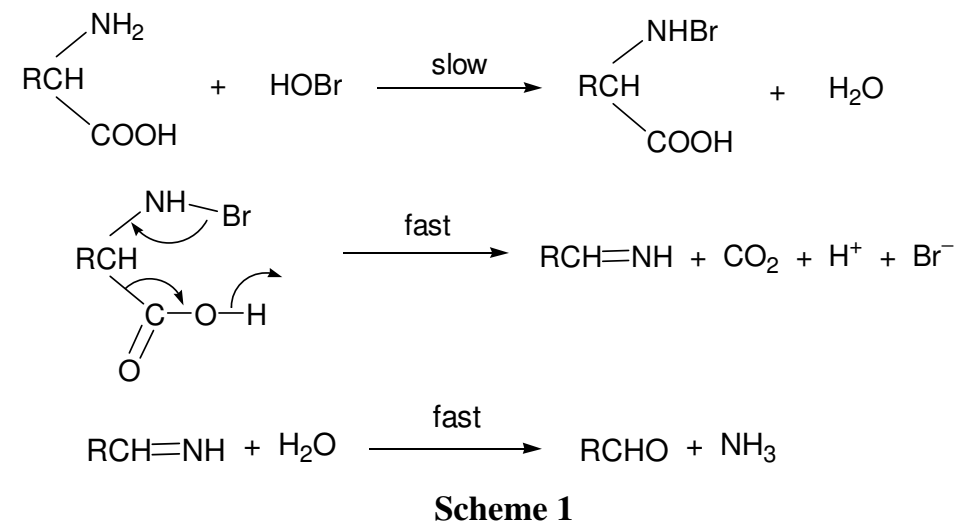

The proposed mechanism is also supported by the moderate value of energy of activation and other thermodynamic parameters. The large negative $\Delta S^{\neq}$indicates the formation of an arranged complex in the rate determining step. 


\section{Conclusion}

In the present kinetic study of the oxidation of isoleucine by $\mathrm{NBP}$ in $\mathrm{HClO}_{4}$ medium, a mechanism involving an electrophilic attack of $\mathrm{HOBr}$ on the amino group of isoleucine has been proposed. This mechanism is supported by the experimental data such as the reaction stoichiometry, the oxidation products and the activation parameters.

\section{Acknowledgment}

The authors thank the college management for providing the necessary facilities.

\section{References}

1. Bishnoi M L and Banerji K K, Tetrahedron, 1985, 41(24), 6047-6050.

2. $\quad$ Dimple Garg and Seema Kothari, Indian J Chem., 2005, 44B, 1909-1914.

3. Singh A K Asian J. Chem. 2003, 15, 1313.

4. Mahadevappa D S, Rangappa K S, Gowda N M M and Gowda B T, Int J Chem Kinet., 1982, 14, 1183.

5. Kutti Rani S, Eswaramoorthy D, Mohamed Bilal T and Palanichamy M, Appl Catal A: General, 2009, 369(1), 1-7.

6. Singh R A, Srivastava V K, Varma J and Kumar M, Asian J Chem., 2007, 19, 1482.

7. Mahadevappa D S, Puttaswamy, and Gowda, N M M, Proc Indian Acad Sci (Chem Sci)., 1988, 100(4), 261.

8. Mahadevappa D S, Sayeed Ahmed M and Gowda N M M, Int J Chem Kinet., 1983, 15, 775 .

9. Puttasamy M and Nirmala Vaz N, J Indian Chem Soc., 2004, 81, 479.

10. Pushphalatha L and Vivekanandan K, J Indian Chem Soc., 2009, 86(5), 475-480.

11. Mohamed Farook N A, Seyed Dameem G A, Murugesan A and Kanagaraj M, E-J Chem., 2004, 1(2), 132-136.

12. Singh A K, Jain B, Negi R, Katre Y, Singh S P and Sharma V K Synth React Inorg, Metal-Org Nano-Metal Chem., 2010, 40, 71-77.

13. Vogel A I, Quantitative Organic Analysis, London, Langman Green, 1958, 708.

14. Feigl F, Spot Tests, Elsevier, Amsterdam, 1954, 20.

15. Srinivasan C, Rajagopal S and Chellamani A, J Chem Soc Perkin Trans 2, 1990, 1839.

16. Gowda B T and Mahadevappa D S, J Chem Soc Perkin Trans 2, 1983, 323. 


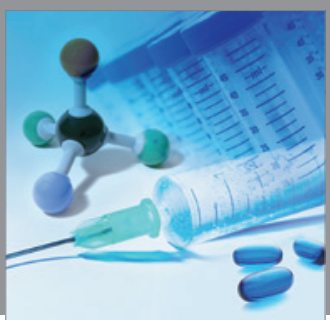

International Journal of

Medicinal Chemistry

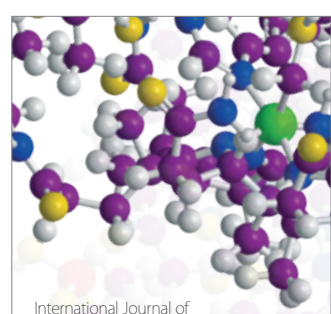

Carbohydrate Chemistry

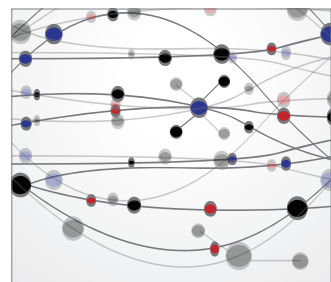

The Scientific World Journal
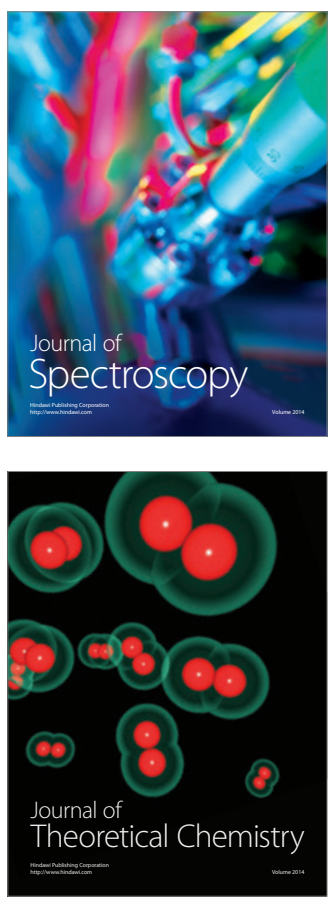
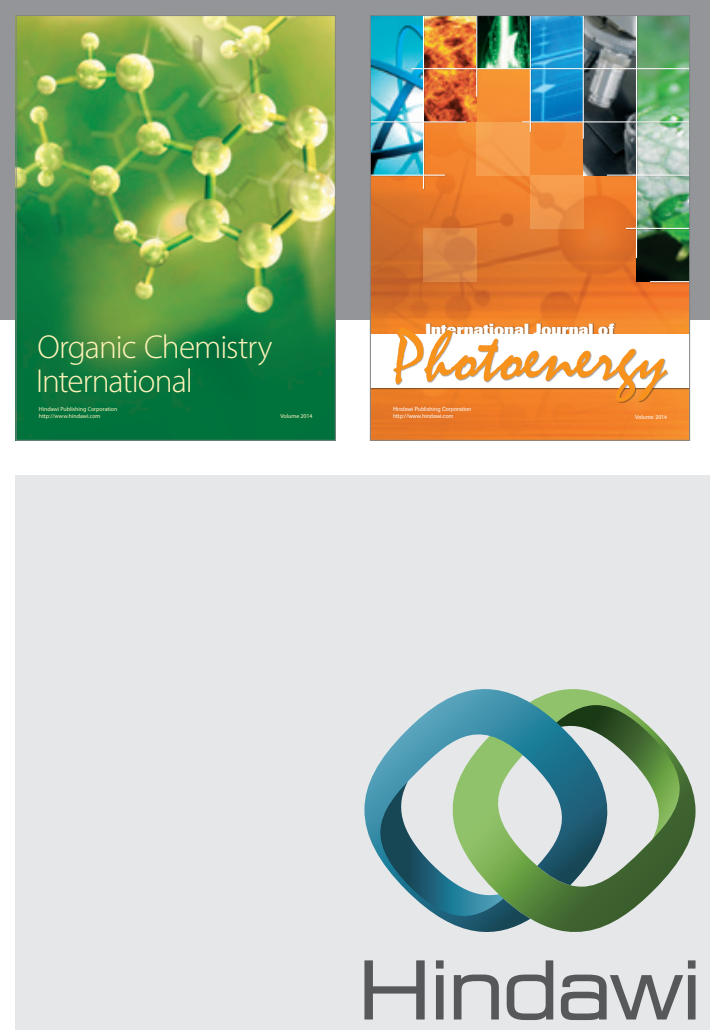

Submit your manuscripts at

http://www.hindawi.com
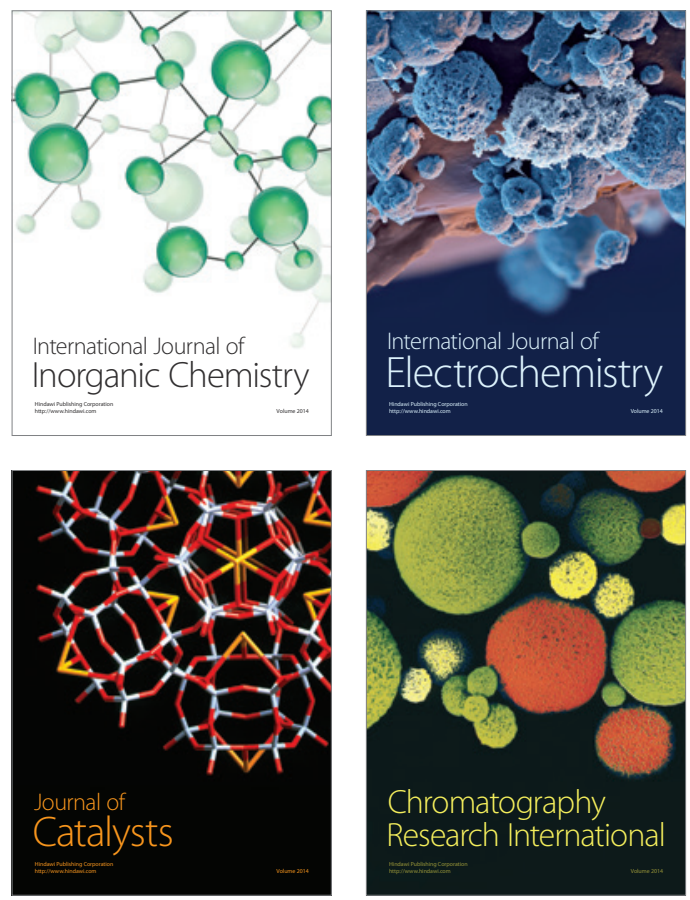
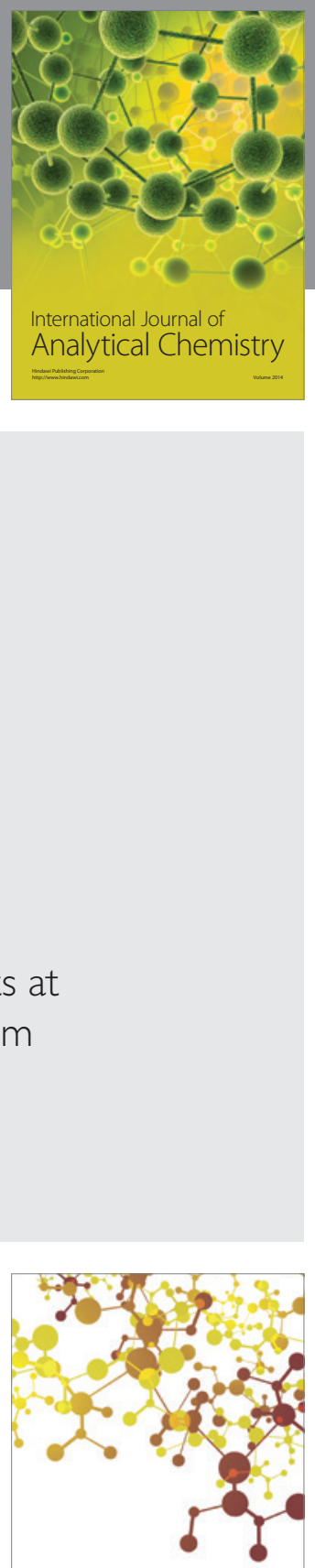

Journal of

Applied Chemistry
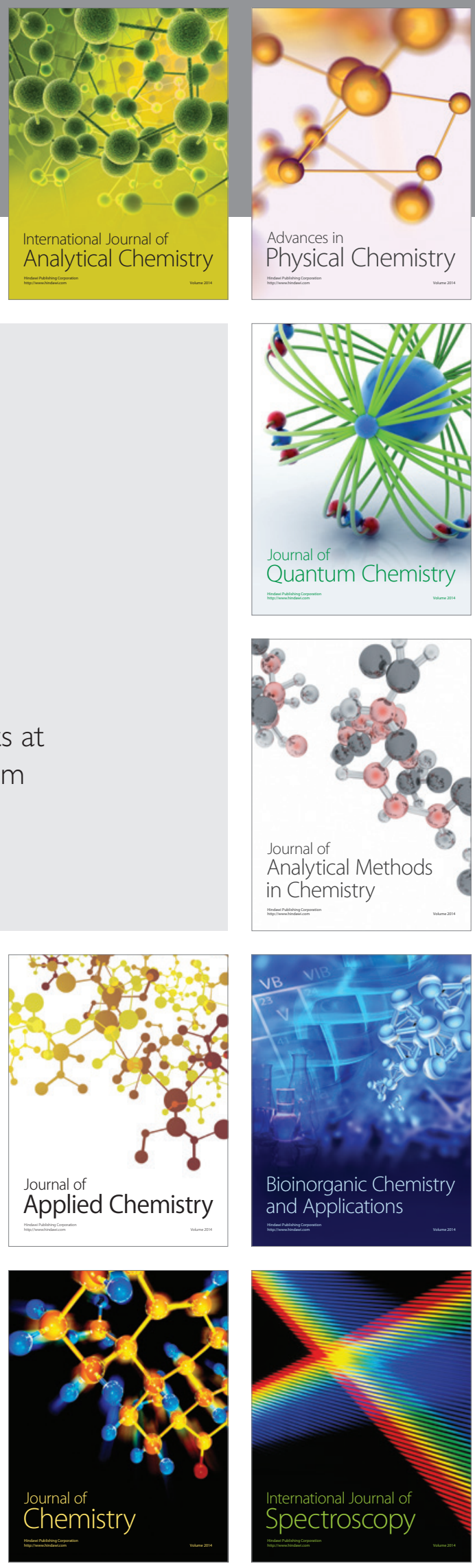